\title{
Characterising the energy performance of centralised HVAC\&R systems in the UK
}

Article

Accepted Version

Shahrestani, M., Yao, R. and Cook, G. (2013) Characterising the energy performance of centralised HVAC\&R systems in the UK. Energy and Buildings, 62. pp. 239-247. ISSN 0378-7788 doi: https://doi.org/10.1016/j.enbuild.2013.03.016 Available at https://centaur.reading.ac.uk/31924/

It is advisable to refer to the publisher's version if you intend to cite from the work. See Guidance on citing.

Published version at: http://dx.doi.org/10.1016/j.enbuild.2013.03.016

To link to this article DOI: http://dx.doi.org/10.1016/j.enbuild.2013.03.016

Publisher: Elsevier

All outputs in CentAUR are protected by Intellectual Property Rights law, including copyright law. Copyright and IPR is retained by the creators or other copyright holders. Terms and conditions for use of this material are defined in the End User Agreement.

\section{www.reading.ac.uk/centaur}

\section{CentAUR}

Central Archive at the University of Reading

Reading's research outputs online 
To cite this article: Mehdi. Shahrestani, Runming. Yao, and Geoffrey K. Cook, Characterising the energy performance of centralised HVAC\&R systems in the UK. Energy and Buildings, 2013. 62(0): p. 239-247.

Link: http://dx.doi.org/10.1016/j.enbuild.2013.03.016

\title{
Characterising the energy performance of centralised HVAC\&R
} systems in the UK

\author{
Mehdi Shahrestani ${ }^{\mathrm{a}}$, Runming Yao ${ }^{\mathrm{a} *}$, Geoffrey K Cook

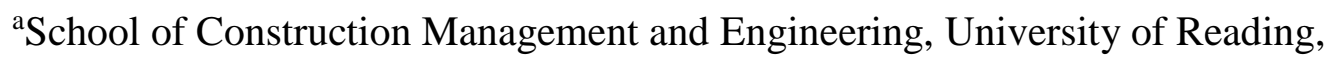 \\ Whiteknights, PO Box 219, Reading, Berkshire, UK \\ *Corresponding author: Runming Yao ${ }^{\mathrm{a}}$
}

\begin{abstract}
Heating, ventilation, air conditioning and refrigeration (HVAC\&R) systems account for more than $60 \%$ of the energy consumption of buildings in the UK. However, the effect of the variety of HVAC\&R systems on building energy performance has not yet been taken into account within the existing building energy benchmarks. In addition, the existing building energy benchmarks are not able to assist decision-makers with HVAC\&R system selection. This study attempts to overcome these two deficiencies through the performance characterisation of 36 HVAC\&R systems based on the simultaneous dynamic simulation of a building and a variety of HVAC\&R systems using TRNSYS software. To characterise the performance of HVAC\&R systems, four criteria are considered; energy consumption, $\mathrm{CO}_{2}$ emissions, thermal comfort and indoor air quality. The results of the simulations show that, all the studied systems are able to provide an acceptable level of indoor air quality and thermal comfort. However, the energy consumption and amount of $\mathrm{CO}_{2}$ emissions vary. One of the significant outcomes of this study reveals that combined heating, cooling and power systems (CCHP) have the highest energy consumption with the lowest energy related $\mathrm{CO}_{2}$ emissions among the studied HVAC\&R systems.
\end{abstract}

Keywords: HVAC\&R system performance, Building energy benchmark, Building energy modelling, HVAC\&R systems, TRNSYS simulation 


\section{Introduction}

According to the international Kyoto protocol (1997), the UK government is committed to reduce greenhouse gas emissions by $30 \%$ and $80 \%$ below the 1990 level respectively by 2020 and 2050 [1]. It is worth noting that, in the UK, buildings account for more than $38 \%$ and $45 \%$ of energy consumption and $\mathrm{CO}_{2}$ emissions respectively [2-4]. Therefore, to achieve these commitments, all new domestic buildings are planned to be zero carbon by 2016 and non-domestic buildings from 2019 [5]. HVAC\&R systems are responsible for more than $60 \%$ of the UK building energy consumption [6]; which underlines the importance of HVAC\&R systems in achieving these commitments.

The national concern regarding the environmental impact of building energy related $\mathrm{CO}_{2}$ emissions along with increasing demands for indoor environmental quality in one hand and the variety of HVAC\&R systems on the other, highlights the importance of choosing the most appropriate system for a building. In the building design process, HVAC\&R system selection is conducted in the early stages of a project [7-9]. Decisions within these stages significantly influence the total building energy performance and establishes up to $90 \%$ of the life time occupants' satisfaction and building running costs [10]. This strategic decision requires a broad insight into the performance characteristics of a variety of HVAC\&R systems. It should be noted that this study is focused on the technical aspects of HVAC\&R systems and economic aspects are not within the scope of work in this research.

The open literature reveals the gap in holistic studies on HVAC\&R system performance characterisation [11, 12]. Despite many studies with a very narrow scope which examined individual topics e.g. the optimisation of HVAC\&R control systems and the simulation/integration of some elements of HVAC\&R systems [13-15], few holistic 
studies have been conducted on HVAC\&R system performance characterisation [1618]. Energy consumption guide 19 (ECG-19), is one the most cited references on the characterisation of the building energy consumption and their corresponding $\mathrm{CO}_{2}$ emissions [18]. ECG-19 categorised the office buildings into four main groups. For each category a breakdown of energy consumption and $\mathrm{CO}_{2}$ emissions are introduced for both "typical" and "good practice" cases based on surveys of a large number of occupied buildings. In one study the Chartered Institution of Building Services Engineers (CIBSE) extended the approach of ECG-19 to other non-domestic buildings in order to support the requirements of display energy certificates [16]. This was subsequently updated to the "energy benchmark technical memorandum 46" (TM46) to simplify the allocation of buildings into different categories [17]. The existing UK building energy benchmark (TM46) has been reviewed based on the latest Display Energy Certificate (DEC) records [19]. Despite the valuable results drawn from real buildings within these three building energy benchmarks [16-18] and also the latest UK energy benchmark review based on the DEC results [19], none of them effectively addresses the influence of different HVAC\&R systems on building energy performance. This deficiency has also been observed in other building energy performance characterisation studies [20, 21]. In most of these studies, survey results did not provide sufficient details to make a clear distinction between surveyed HVAC\&R systems and their energy consumption [20-22]. Consequently, this deficiency has been coarsely overcome by assuming a typical HVAC\&R system for each building category $[18,20]$. Therefore, the aim of this study is to overcome this deficiency through an investigation of the performance of a variety of HVAC\&R systems within a robust framework based on dynamic simulation of a prototypical office building. 


\section{Research design}

In this study, simultaneous dynamic simulation of a typical office building and HVAC\&R systems are adopted to analysis the energy performance of different parts of HVAC\&R systems. The open literature introduces more than twenty simulation packages for building dynamic performance simulations [23, 24]. Several researches are conducted using different simulation packages such as TRNSYS, ESP-r, EnergyPlus and other dynamic simulation tools $[23,24]$, but in general terms, all of these tools are validated by well-recognised academic organisations. Crawley et al. [23, 24] have conducted a comprehensive comparison study for the existing simulation tools. It shows that Transient System Simulation Tool (TRNSYS) is one of the best options for HVAC\&R system studies by providing more features for HVAC\&R systems. In TRNSYS the components are configured and assembled using a fully integrated visual interface with ability to develop new components [23, 24]. In terms of software validation, TRNSYS is one of the listed simulation programs in the Building Energy Software Tools Directory of the US Department of Energy (DoE) and International Energy Agency (IEA) [25]. Moreover, several successful studies have been conducted using this tool [26-30]. Hence, the last Version of TRNSYS simulation package (Version 17.00.0019) is selected to analyse the dynamic performance of a variety of HVAC\&R systems in this study. In performance evaluation of HVAC\&R systems using TRNSYS, four major criteria are considered within the scope of work in this research. These criteria include energy consumption, $\mathrm{CO}_{2}$ emissions, thermal comfort and indoor air quality. In the following sections, a prototypical office building and HVAC\&R systems that are investigated in this research are described in detail. 


\section{Building descriptions}

In this study a prototypical daylit cellular office building has been selected to form a basis for the performance evaluation of a variety of HVAC\&R systems. This built form is chosen because it accounts for more than $67 \%$ of office buildings in England and Wales [31]. The building has four floors with a total floor area of $1920 \mathrm{~m}^{2}$. Room depth (distance from windows) is considered less than $6 \mathrm{~m}$ to comply with the definition of daylit cellular office buildings [32].

To identify the amount of glazing area within the case study building, the ratio of glazing per floor area $(\mathrm{G} / \mathrm{F})$ is assumed as the average values of $\mathrm{G} / \mathrm{F}$ for cellular office buildings with different building structures as reported by NDBS project [33]. An isometric model and typical plan of the case study office building is shown in

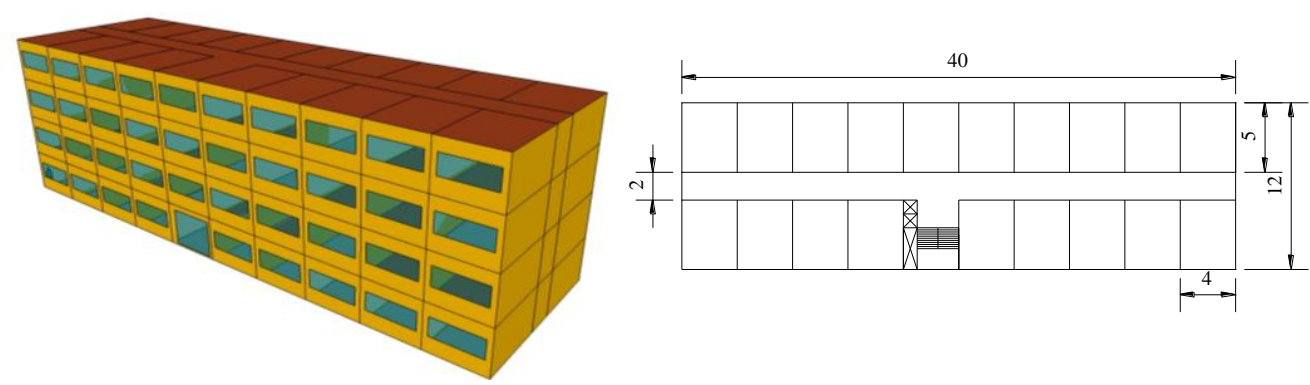

Figure 1: Isometric model and typical plan of the case study office building. (All dimensions in meters)

Overall heat transfer coefficient of walls, roof and windows are respectively assumed as $0.28,0.18$ and $1.8\left(\mathrm{~W} / \mathrm{m}^{2} . \mathrm{C}\right)[34]$ and the infiltration rate is set to 0.3 air change per hour [35]. To achieve an acceptable indoor air quality level, the ventilation rate is set to 10 (L/s.person) [36]. Occupancy density of the prototypical building is assumed to be $10\left(\mathrm{~m}^{2} /\right.$ person) [35]. For typical office activities, human body sensible and latent heat rejection are respectively defined as 75 and 55 (W/person) [35]. To achieve an 
illuminance of 300-500 (lx), a power load of $15\left(\mathrm{~W} / \mathrm{m}^{2}\right)$ is assumed [37]. Finally, the electrical equipment load is assumed as 200 (W/person) [35]. With regard to the occupancy pattern, the building is in use only during weekdays between 8 am to $6 \mathrm{pm}$. Indoor design temperature is set to $23^{\circ} \mathrm{C}$ in cooling mode and $22^{\circ} \mathrm{C}$ during heating mode. In heating mode, the humidity control is set to $45 \%$ relative humidity [35]. It should be noted that considering a variety of profiles for internal energy loads and delighting control along with different forms of possible shadings is not within the scope of this research. The prototypical building and the HVAC\&R systems are created in TRNSYS and simulated using the London-Gatwick weather data file. This data file has been developed based on a comprehensive meteorological reference (Meteonorm) used by TRNSYS simulation package [33].

\section{HVAC\&R systems}

In the open literature, there are several different approaches to the categorisation of HVAC\&R systems [16, 38-41]. Among them, CIBSE categorised HVAC\&R systems into three main groups; centralised air systems, partially centralised air/water systems and local systems [16]. This study is mostly concerned with the energy performance characterisation of a variety of centralised HVAC\&R systems as applied to the case study building. Three primary and 12 secondary systems which in total form 36 permutations of primary and secondary systems are investigated within this study. The primary systems include three combinations of heating and cooling systems (Table.1). The secondary systems include constant air volume (CAV) and variable air volume (VAV) distribution systems with heat recovery, economiser and terminal reheat units and provide 12 permutations which are described in Table 2 . 
Table 1: Primary systems.

\begin{tabular}{|l|l|}
\hline No. & Heating and cooling parts \\
\hline 1 & Gas boiler with reciprocating air cooled chiller \\
\hline 2 & Gas boiler with absorption chiller with cooling tower \\
\hline 3 & $\begin{array}{l}\text { Combined heat and power (CHP) with absorption chiller and cooling } \\
\text { tower (CCHP) }\end{array}$ \\
\hline
\end{tabular}

Table 2: Secondary systems.

\begin{tabular}{|l|l|l|l|}
\hline No. & Part 1 & part 2 & part 3 \\
\hline 1 & Constant air volume (CAV) & - & - \\
\hline 2 & Variable air volume (VAV) & - & - \\
\hline 3 & Constant air volume (CAV) & Heat recovery & - \\
\hline 4 & Variable air volume (VAV) & Heat recovery & - \\
\hline 5 & Constant air volume (CAV) & Economiser & - \\
\hline 6 & Variable air volume (VAV) & Economiser & - \\
\hline 7 & Constant air volume (CAV) & - & Reheat coil \\
\hline 8 & Variable air volume (VAV) & - & Reheat coil \\
\hline 9 & Constant air volume (CAV) & Heat recovery & Reheat coil \\
\hline 10 & Variable air volume (VAV) & Heat recovery & Reheat coil \\
\hline 11 & Constant air volume (CAV) & Economiser & Reheat coil \\
\hline 12 & Variable air volume (VAV) & Economiser & Reheat coil \\
\hline
\end{tabular}

The temperature of the supply chilled water $\left(\mathrm{T}_{\text {schw }}\right)$ and supply hot water $\left(\mathrm{T}_{\text {shw }}\right)$ for all primary systems are respectively set to $6^{\circ} \mathrm{C}$ and $80^{\circ} \mathrm{C}$ [16] (Figure 2). The energy efficiency of primary systems are defined based on actual manufacturer information within the recommended range according to ASHRAE standard 90.1 and British standard BS/EN:15316 [42, 43]. Table shows the recommended minimum efficiency of the main primary systems along with the assumed values (based on manufacturer's 
product specifications) that are taken into account in this study. It should be noted that the efficiencies mentioned in Table 3 are compulsory indicators that proves the compliance of equipment with the existing standards $[42,43]$ and TRNSYS simulates the HVAC\&R systems based on actual full/partial loads.

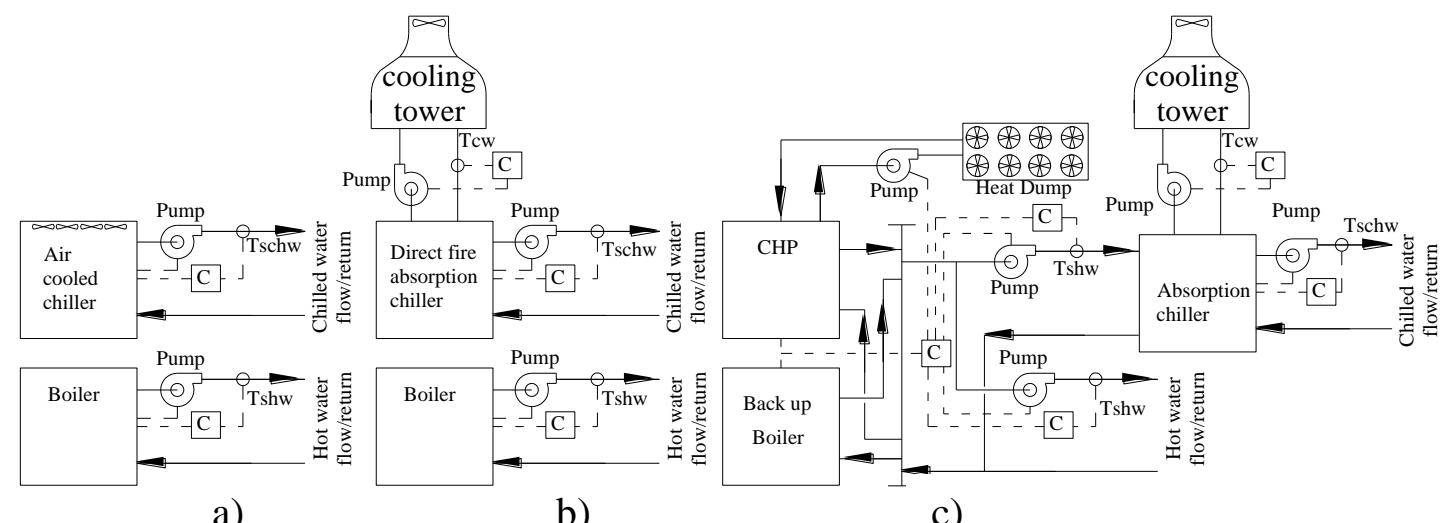

Figure 2: Primary systems a) boiler with air cooled chiller, b) boiler with absorption chiller and cooling tower, c) CHP with absorption chiller and cooling tower (CCHP).

Table 3: Recommended minimum energy efficiency required and the values assumed in this study.

\begin{tabular}{|l|l|l|}
\hline \multirow{2}{*}{ System } & Energy efficiency $*$ \\
\cline { 2 - 3 } & Min requirements $[42,43]$ & This study \\
\hline Air cooled reciprocating chiller & $\mathrm{COP} \geq 2.802$ & $\mathrm{COP}=3.2$ \\
\hline Double effect absorption chiller & $\mathrm{COP} \geq 1$ & $\mathrm{COP}=1.2$ \\
\hline Gas boiler & $\mathrm{Et} \geq 80 \%$ & $\mathrm{Et}=85 \%$ \\
\hline Combined heat and power $(\mathrm{CHP})$ & $\mathrm{Te}=73 \%-95 \%$ & $\mathrm{Te}=80 \%$ \\
\hline $\begin{array}{l}\text { Notes- Et: Thermal efficiency ; COP: Coefficient of performance, Te: Total } \\
\text { efficiency, *:Energy efficiency under test conditions }[42,43]\end{array}$ \\
\hline
\end{tabular}

In the secondary systems, the air distribution in VAV arrangement provides the required indoor air temperature by changing the amount of delivered air (Figure a). Heating and cooling coils control the supply air temperature $\left(\mathrm{T}_{\mathrm{sa}}\right)$ while the VAV fan changes the air 
flow rate. The Indoor temperature moves towards the desired indoor design temperature by changing the opening fraction of the supply air damper. These changes directly influence the performance curve of the air distribution system; therefore to avoid either over or under delivery of the air into the distribution system, the VAV fan keeps the air distribution system pressure at a set level $\left(\mathrm{P}_{\text {set }}\right)$. Due to the design pressure loss of the VAV system, $\mathrm{P}_{\text {set }}$ is defined as $450(\mathrm{~Pa})$ to ensure that required amount of air would be available in the distribution system at all partial load circumstances. In the case of utilising reheat coils, additional control would be available to cover the rapid changes on heating and cooling demands which can not be tracked by the VAV fan. Also, the heat recovery between exhaust and fresh air streams is an option which has been investigated within the heating mode. Heat recovery efficiency of the heat recovery unit is assumed equal to $70 \%$. It should be noted that the performance of heat recovery units is simulated based on recovery efficiency of the unit together with both the temperature and the humidity of air streams. Also, an economiser with temperature control capability is another energy saving option which is used in the cooling mode. A temperature control economiser achieves the predefined mixed air temperature $\left(\mathrm{T}_{\mathrm{ma}}\right)$ through the maximum use of the outdoor air when its temperature $\left(\mathrm{T}_{\mathrm{fa}}\right)$ is below the return air temperature $\left(T_{\mathrm{re}}\right)$. In this study the economiser mixed air temperature $\left(\mathrm{T}_{\mathrm{ma}}\right)$ is set to $15^{\circ} \mathrm{C}$ to make use of the free cooling opportunity in the UK.

In the CAV air distribution system (Figure 3b); the fan operates at constant speed. In order to maintain the desired indoor temperature; heating and cooling coils change the supply air temperature $\left(\mathrm{T}_{\mathrm{sa}}\right)$ according to the temperature feedback from the return air $\left(\mathrm{T}_{\mathrm{ra}}\right)$ (Figure $\mathrm{b}$ ). Similar to the VAV system, a heat recovery and an economiser option have been investigated. For both air distribution systems (CAV and VAV), an electrical 
humidifier is installed to provide an indoor relative humidity level of $45 \%$. The humidifier gets feedback from the return air relative humidity $\left(\mathrm{RH}_{\mathrm{ra}}\right)$ and alters this value to the desired set point.

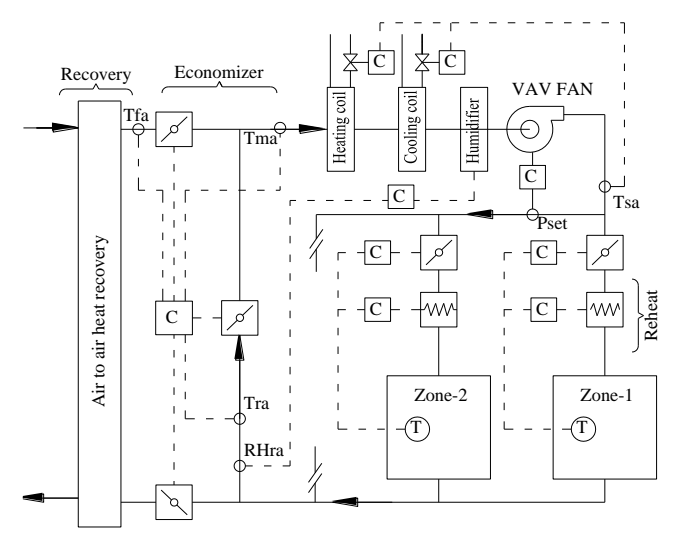

a)

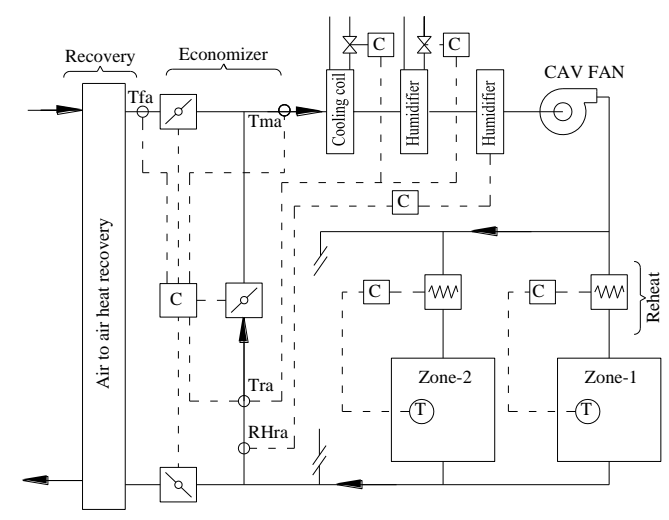

b)

Figure 3: Schematic diagram for secondary systems a) VAV and b) CAV both with reheat coil, economiser and heat recovery options.

\section{Analytical calculations for building heat and moisture mass transfer:}

TRNSYS calculations are based on the heat balance method. Time dependent indoor air temperature $\left(T_{i}\right)$ is calculated by taking into account the space capacitance $\left(C_{i}\right)$ and net heat gain $\left(\dot{Q}_{i}\right)$ through the following energy balancing equations [33]:

$$
\begin{aligned}
& C_{i} \frac{d T_{i}}{d t}=\dot{Q}_{i} \\
& \dot{Q}_{i}=\dot{q}_{c r, s u r f, i}+\dot{q}_{c, i n f, i}+\dot{q}_{c, v e n t, i}+\dot{q}_{c, c p l g, i}+\dot{q}_{c, i g, i} \\
& \dot{q}_{c r, s u r f, i}=\frac{1}{R_{s t a r, i}}\left(T_{s t a r, i}-T_{i}\right) \\
& \dot{q}_{c, \text { inf } i}=\dot{m}_{\text {inf } i} C_{p}\left(T_{a}-T_{i}\right) \\
& \dot{q}_{c, v e n t, i}=\dot{m}_{v e n t, i} C_{p}\left(T_{v e n t}-T_{i}\right) \\
& \dot{q}_{c, c p l g, i}=\sum_{1}^{n} \dot{m}_{c p l g, n} C_{p}\left(T_{n}-T_{i}\right)+\sum_{1}^{e} \dot{m}_{c p l g, e} C_{p}\left(T_{b, e}-T_{i}\right)
\end{aligned}
$$


Where, $\dot{q}_{c r, s u r f, i}, \dot{q}_{c, i n f, i}, \dot{q}_{c, v e n t, i}, \dot{q}_{c, c p l g, i}$ and $\dot{q}_{c, i g, i}$ represent, the combined (convection and radiation) heat gain from inside surfaces, the convection heat gain corresponding to air infiltration, the convection heat gain corresponding to ventilation, the convective gain due to the air flow from the adjacent airnode or boundary conditions and internal convective gain respectively. $\dot{m}_{i n f, i}, \dot{m}_{v e n t, i}, \dot{m}_{c p l g, n}$ and $\dot{m}_{c p l g, e}$ are the infiltration mass flow rate, the ventilation mass flow rate, the air mass flow rate from adjacent spaces and the air mass flow rate from known boundary surfaces. Finally, $\mathrm{T}_{\text {star }}$ is an artificial temperature node to calculate parallel energy flow from an internal surface by convection to the airnode and by radiation to the other surfaces. Also, $\mathrm{R}_{\text {star }}$ is an artificial conduction resistance to calculate the energy flow from an internal surface to the airnode [33]. These two parameters are calculated in each simulation time step by taking into account the following radiation heat flow equation:

$$
\dot{q}_{r, w}=\dot{q}_{r, i g}+\dot{q}_{s o l, w}+\dot{q}_{\text {long,w }}+\dot{q}_{r, \text { wall-gain }}
$$

Where, $\dot{q}_{r, w}, \dot{q}_{r, i g}, \dot{q}_{s o l, w}, \dot{q}_{\text {long,w }}$ and $\dot{q}_{r, \text { wall-gain }}$ represent, the radiation gain from wall surfaces, the radiation internal gain, the radiation solar gain, the long-wave radiation between internal surfaces and the user-specified heat flow to the wall or windows.

The time dependent indoor air humidity $(\omega)$ is calculated through the following moisture balancing equations in an effective capacitance humidity model [33]:

$$
\begin{aligned}
& M_{e f f, i} \frac{d \omega_{i}}{d t}=\dot{m}_{i n f, i}\left(\omega_{a}-\omega_{i}\right)+\dot{m}_{v e n t, i}\left(\omega_{v e n t, i}-\omega_{i}\right)+\dot{W}_{i g, i}+\sum_{1}^{n} \dot{m}_{c p l g, n}\left(\omega_{n}-\omega_{i}\right) \\
& M_{e f f, i}=\text { Ratio } M_{\text {air }, i}
\end{aligned}
$$

Where, $M_{e f f, i}$ and $M_{a i r, i}$ represent the effective moisture capacitance of the entire room and the moisture capacitance of the room air respectively. Also, 'Ratio' represents the 
ratio between room effective moisture capacitance and room air moisture capacitance and finally, $\dot{W}_{i g, i}$ represents the internal moisture gain.

\section{Mathematical approach for HVAC\&R systems performance evaluation:}

The mathematical approach for performance evaluation of HVAC\&R systems is introduced here. Firstly, the energy consumption of the systems are evaluated using the outcome of simultaneous simulation of the HVAC\&R systems and the building. It is defined according to the following equation:

$T E C=\sum_{1}^{j} E C_{j}$

Where TEC is the annual energy consumption of the entire HVAC\&R system and $\mathrm{EC}_{\mathrm{J}}$ represents the energy consumption of the jth HVAC\&R process. Also, the energy related $\mathrm{CO}_{2}$ emissions of $\mathrm{HVAC} \& \mathrm{R}$ systems are calculated by considering $\mathrm{CO}_{2}$ emission factors of gas and electricity from the UK National Grid, equal to 0.19 and $0.55\left(\mathrm{~kg} \mathrm{CO}_{2} / \mathrm{kWh}\right)$ respectively [17].

Essentially the main goal of utilising HVAC\&R systems is to provide acceptable indoor environmental quality. In this study user satisfaction is measured by considering the thermal comfort and the indoor air quality according to the model introduced by TRNSYS [33] based on the Standard BS EN 15251 [44]. This standard categorised the indoor air quality and thermal comfort into four main groups (Table 4). The first three groups are recommended; but, the forth category is only acceptable if it occurs for a limited time in a year [44]. 
Table 4: Thermal comfort and indoor air quality categories [44].

\begin{tabular}{|l|l|l|l|}
\hline \multirow{2}{*}{$\begin{array}{l}\text { Category } \\
\text { Rating grades) }\end{array}$} & $\begin{array}{l}|l| \\
\text { Phedicted Percentage } \\
\text { Dissatisfied (PPD) }\end{array}$ & $\begin{array}{l}\text { Predictive mean } \\
\text { vote }(\text { PMV) }\end{array}$ & $\begin{array}{l}\mathrm{CO}_{2} \text { concentration } \\
(\mathbf{P P M})\end{array}$ \\
\hline 1 & $\mathrm{PPD}<6 \%$ & $-0.2<\mathrm{PMV}<+0.2$ & $\mathrm{PPM}<750$ \\
\hline 2 & $\mathrm{PPD}<10 \%$ & $-0.5<\mathrm{PMV}<+0.5$ & $\mathrm{PPM}<900$ \\
\hline 3 & $\mathrm{PPD}<15 \%$ & $-0.7<\mathrm{PMV}<+0.7$ & $\mathrm{PPM}<1200$ \\
\hline 4 & $\mathrm{PPD}>=15 \%$ & $-0.7>=\mathrm{PMV}>=0.7$ & $\mathrm{PPM}>=1200$ \\
\hline
\end{tabular}

Total grade of thermal comfort (TGTC) for all spaces in a year is taken into account to measure the level of comfort according to the following equations:

$T G T C=\frac{\sum_{1}^{i} \sum_{1}^{h}\left(\operatorname{TRG}_{i, h} \times X_{i, h}\right)}{\sum_{1}^{i} \sum_{1}^{h} X_{i, h}}$

Where $\mathrm{TRG}_{\mathrm{i}, \mathrm{h}}$ and $\mathrm{X}_{\mathrm{i}, \mathrm{h}}$ respectively represents the thermal comfort rating grade (according to Table 4) and the number of occupants in the space $\mathrm{i}$ at hour h. Using a similar approach, the total grade for indoor air quality (TGIAQ) for all spaces in a year is used to measure the level of indoor air quality according to the following equations:

$T G I A Q=\frac{\sum_{1}^{i} \sum_{1}^{h}\left(\operatorname{IRG}_{i, h} \times X_{i, h}\right)}{\sum_{1}^{i} \sum_{1}^{h} X_{i, h}}$

Where $I R G_{i, h}$ and $X_{i, h}$ respectively represent the indoor air quality rating grade (according to Table 4), and the number of occupants in the space $\mathrm{i}$ at hour $\mathrm{h}$. 


\section{Results}

The simultaneous dynamic simulation of the building and a variety of HVAC\&R systems culminated in a series of results giving the breakdown of end-use energy consumption and amount of energy related $\mathrm{CO}_{2}$ emissions produced by the different HVAC\&R systems. Also, it provides measures for thermal comfort and indoor air quality associated with HVAC\&R systems which are shown in Table 5.

Table 5 demonstrates the annual occurrence percentage of the studied HVAC\&R systems in each category of thermal comfort and indoor air quality as introduced in BS EN 15251 [44]. This table highlights that the studied HVAC\&R systems performed within the first three recommended categories of thermal comfort and indoor air quality for $96-100 \%$ of the time within a year (Table 5). Therefore, the energy consumption and $\mathrm{CO}_{2}$ emissions analyses would be more indicative for the characterisation of the variety of HVAC\&R systems.

Table 5: Annual occurrence percentage of the HVAC\&R systems performance under each category of thermal comfort and indoor air quality.

\begin{tabular}{|l|l|l|}
\hline $\begin{array}{l}\text { Category } \\
\text { (Rating grades) } \\
\text { BS EN 15251[44] }\end{array}$ & $\begin{array}{l}\text { Total grade thermal comfort } \\
\text { (TGTC) occurrence percentage } \\
\text { in each category }\end{array}$ & $\begin{array}{l}\text { Total grade indoor air quality } \\
\text { (TGIAQ) occurrence } \\
\text { percentage in each category }\end{array}$ \\
\hline 1 & $61-73 \%$ & $31-52 \%$ \\
\hline 2 & $84-100 \%$ & $94-100 \%$ \\
\hline 3 & $96-100 \%$ & $96-100 \%$ \\
\hline 4 & $0-4 \%$ & $0-4 \%$ \\
\hline
\end{tabular}

In order to present the results in a format similar to the breakdown of energy used in the UK building energy benchmarks [16, 18], the energy consumption of HVAC\&R systems are classified into five main groups: 
1. Energy use for cooling

2. Central heating energy consumption

3. Humidification energy use

4. Auxiliary energy including energy required for running fans and pumps

5. Energy consumption for reheat process

Figures 4,5 and 6 demonstrate the energy consumption and energy related $\mathrm{CO}_{2}$ emissions of the 36 permutations of primary and secondary HVAC\&R systems. These results are normalised with respect to building floor area in order to be comparable with existing building energy benchmarks [16-18]. For the same reason, these energy consumptions results represent the real demand of building to natural gas and electricity rather than representing the equivalent primary energy used in building.
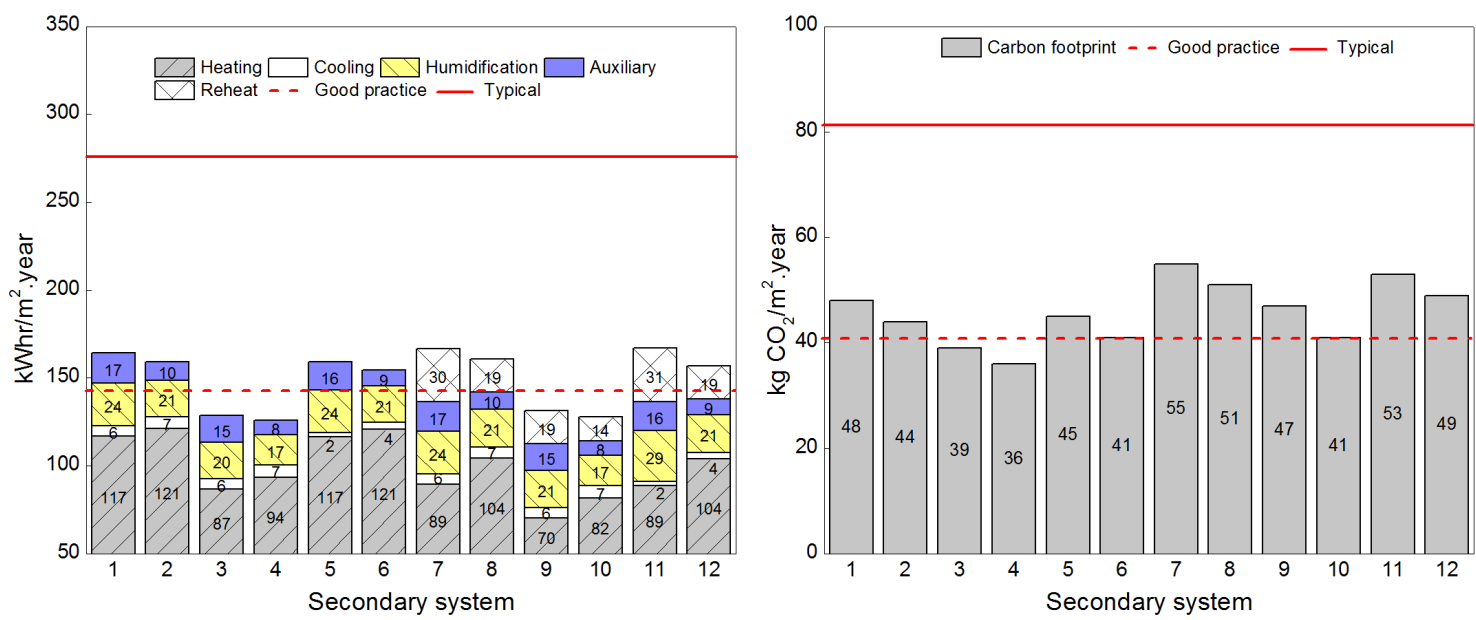

a)

b)

Figure 4: First primary systems (gas boiler with reciprocating chiller) a: energy consumption b: energy related $\mathrm{CO}_{2}$ emissions. 


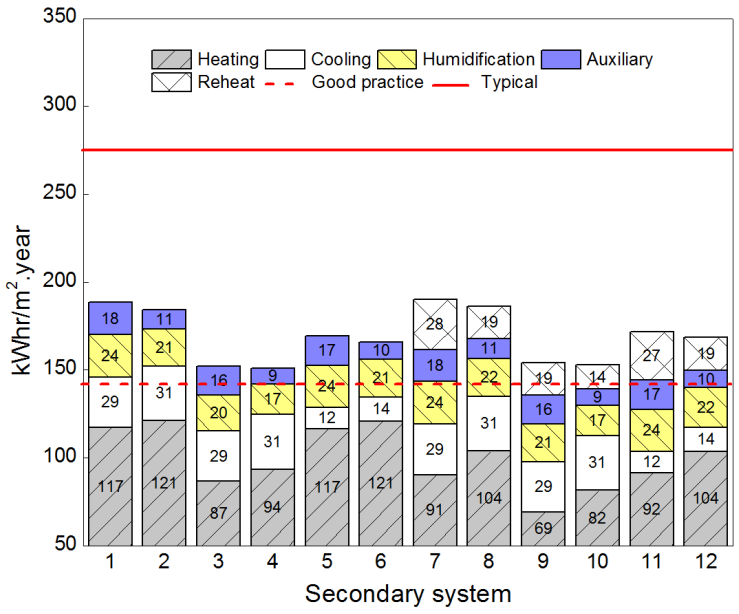

a)

Figure 5: Second primary systems (gas boiler with absorption chiller) a: energy consumption b: energy related $\mathrm{CO}_{2}$ emissions.

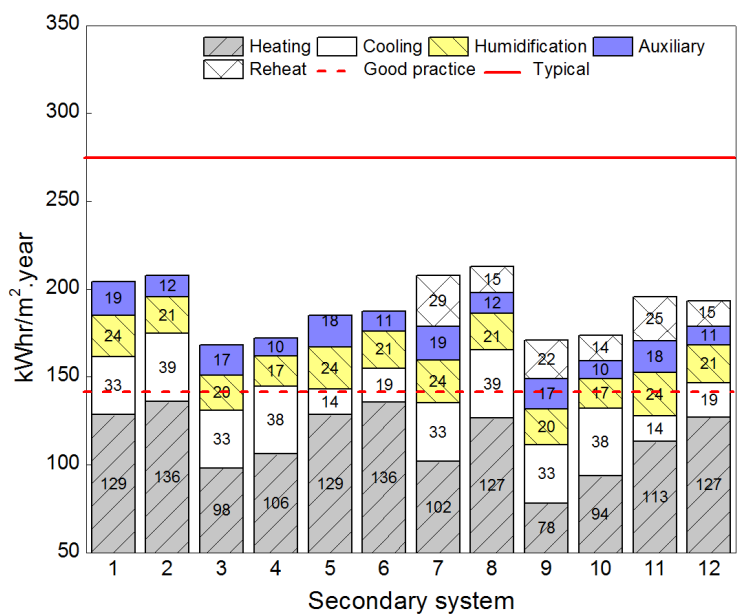

a)

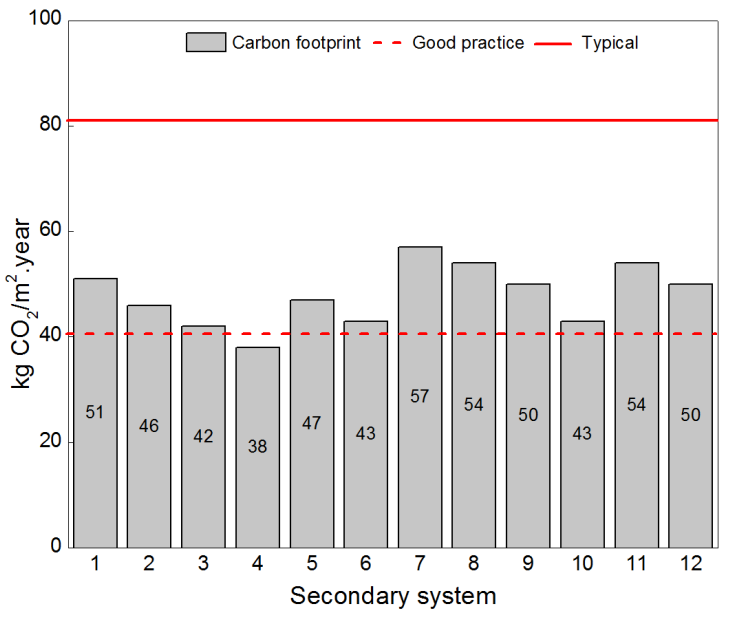

b)

Figure 6: Third primary systems-CCHP (absorption chiller with CHP) a: energy consumption b: energy related $\mathrm{CO}_{2}$ emissions.

To validate the results, ECG-19 [18] has been used because it is a widely cited reference in the most of the building energy benchmarking studies in the UK [16, 17, 45]. In this benchmark, energy consumption and $\mathrm{CO}_{2}$ emissions of a standard air conditioned building are described as two levels "good practice" and "typical". The reference building is assumed to be equipped with an air cooled chiller, a gas boiler and a VAV air distribution system [18]. This assumption is similar to the combination of the first 
primary system (Table ) and the second secondary system (Table 2) which has been investigated in this study.

Simulation results reveal that both the energy consumption and $\mathrm{CO}_{2}$ emissions of this system are within the ECG-19 [18] ranges and about 15\% higher than the good practice (Figures 4).

According to the recommendation of building energy benchmarking references [16, 18], performance of office buildings with a HVAC\&R systems other than the mentioned standard system, should be appraised by their total $\mathrm{CO}_{2}$ emissions. This approach has been adopted in this study to compare the simulated performance of a variety of HVAC\&R systems with the standard benchmark building in Figures $4 b, 5 b$ and 8 .

For HVAC\&R systems which are linked to a CCHP system (third primary system), the amount of generated electricity (Figure 7) is also needed to compare the results. It should be noted that, regarding to the variation of building energy demand under different secondary systems, the CHP unit works with different partial load regimes and generates different amount of electricity.

The CHP unit of the CCHP system reduces the dependency of the building on the National Grid because of the amount of generated electricity. Consequently, the corresponding amount of $\mathrm{CO}_{2}$ emissions from national grid electricity should be extracted from the $\mathrm{CO}_{2}$ emissions of the systems linked to the CCHP system (Figure 6b) to provide the actual $\mathrm{CO}_{2}$ emissions which is shown in (Figure 8). 


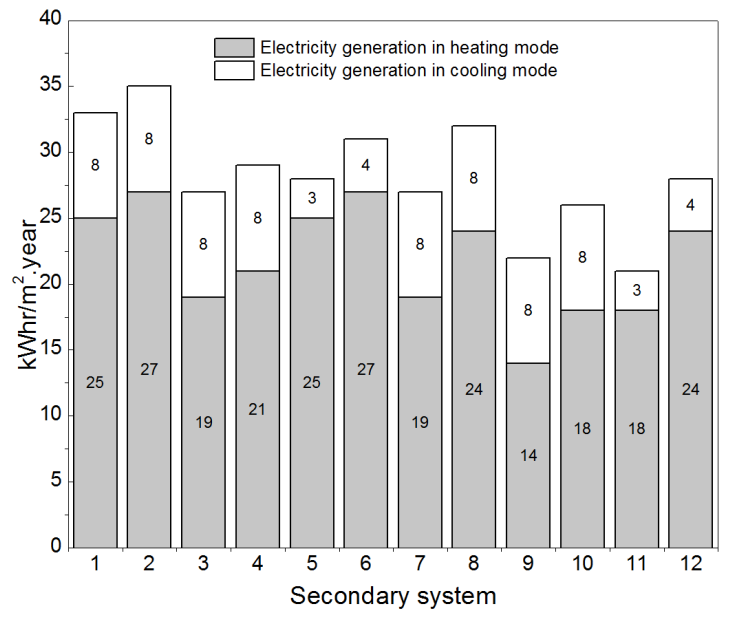

Figure 7: The generated electricity by the third primary system (CCHP)

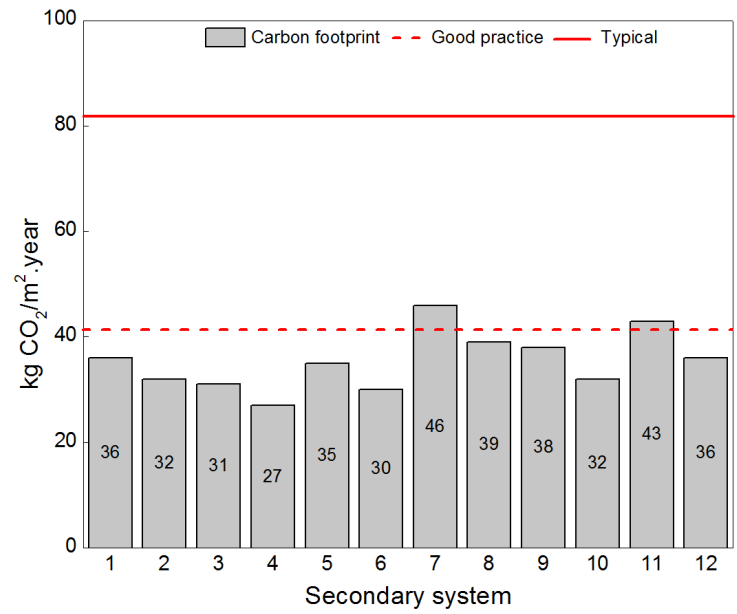

Figure 8: The actual energy related $\mathrm{CO}_{2}$ emissions of the third primary system (CCHP) by considering the amount of generated electricity.

\section{Discussions}

To analysis the results, two approaches are adopted; a detailed comparison and a holistic approach. In the detailed approach, when comparing the total energy consumption of systems (Figures 4a, 5a and 6a) it is revealed that, apart from the type of primary systems, auxiliary and total energy consumption of the HVAC\&R system equipped with VAV air distribution (even secondary systems) are respectively $15-35 \%$ and $5-15 \%$ lower than corresponding CAV air distribution (odd secondary systems). This trend is 
also true for secondary systems linked to the CCHP system after taking into account the amount of electricity generation by the CHP unit (Figure 7). In addition, systems connected to the VAV air distribution system use slightly higher energy to meet the required heating and cooling demands compared with CAV air distribution. This has also been observed by Korolija et al. [45]. It is believed that this trend is mainly because of the higher air flow rate in CAV systems which results in higher heat dissipation to the supply air from fan units [45]. In addition, this study reveals that VAV systems are able to track the desired indoor temperature better than CAV systems. In the other words, the closer to the indoor desired temperature, the more energy would be used.

In Figures 4a, 5a and 6a, comparing the energy consumption of secondary systems numbers 3, 4, 9 and 10 respectively with numbers $1,2,7$ and 8 demonstrates that HVAC\&R systems which are equipped with a heat recovery unit use $12-28 \%$ less energy to provide the required heating regardless of the type of primary systems. Using the same approach, when comparing the energy consumption of the secondary systems numbers 5, 6, 11 and 12 respectively with systems numbers 1, 2, 7 and 8 reveals that using an economiser in the secondary systems reduces the energy consumption for cooling by $33-65 \%$. This is mainly because of the mild weather condition for London in summer. Also, Figures 4a, 5a and 6a reveal that using reheat coil does not significantly affect the total energy use when comparing systems number 1-6 with systems number 712 regardless of the type of primary system.

Analysis of the results using a holistic approach, comparison of energy consumption results (Figures 4a, 5a and 6a) reveals that reciprocating chillers with boiler (first primary system) has the lowest and the CCHP system (third primary system) has the highest total energy demand when connected to an identical secondary system. Also, the 
energy related $\mathrm{CO}_{2}$ emissions of HVAC\&R systems (Figures $4 \mathrm{~b}$ and $5 \mathrm{~b}$ ) shows that, even though the energy consumption of secondary systems linked to an absorption chiller with a gas boiler is higher than the corresponding secondary systems linked to a reciprocating chiller with a gas boiler (Figure $4 \mathrm{a}$ and 5a), the $\mathrm{CO}_{2}$ emissions of the former are not significantly higher than the latter (Figure $4 b$ and $5 b$ ).

The $\mathrm{CO}_{2}$ emissions shown in Figure 8 reveal that utilising a CCHP system reduces the amount of $\mathrm{CO}_{2}$ emissions up to $30 \%$ compared to the other systems by the simultaneous generation of heating, cooling and power. This is based on the difference between the $\mathrm{CO}_{2}$ emission factor of natural gas and electricity delivered by National Grid [17].

In summary, among the studied systems, higher and lower energy demands are associated with the CCHP system (Figure 6a) when linked to the VAV system with reheat (eighth secondary system) and reciprocating chiller with a gas boiler (Figure 4a) when linked to the VAV system with heat recovery unit (fourth secondary system) respectively.

In terms of $\mathrm{CO}_{2}$ emissions, the best performance is delivered by the CCHP system (Figure 8) when linked to the VAV system with heat recovery (fourth secondary system); whereas, the highest pollution is produced by the absorption chiller and boiler (Figure 5b) when linked to the CAV system with terminal reheat coils (seventh secondary system).

With the same approach proposed in the ECG19 [18], the outcomes of this research could be extended into the other climates using degree day theory [46, 47]. This provides the opportunity to use the outcome of this research to the other cities regardless of their geographical location. 


\section{Conclusions}

The aim of this study was to enhance the existing building energy benchmarks approach in the performance characterisation of a variety of HVAC\&R systems. The investigation of the energy consumption and $\mathrm{CO}_{2}$ emissions of different HVAC\&R systems together with the consideration of the achieved levels of indoor air quality and thermal comfort, are further strengths of this study.

A prototypical office building has been used as a case study; specifications of the building are defined based on the outcome of previous studies of non-domestic building stock in the UK and the latest regulations. Results of this study show that, in the secondary part of HVAC\&R systems, utilising the VAV system (instead of CAV system) reduces the auxiliary energy consumption by $15-35 \%$ which is equal to a $5-15 \%$ reduction in the total energy consumption of the building. In addition, the amount of energy used to meet the heating and cooling demands in VAV systems is slightly higher than in CAV systems. It has also shown that utilising a heat recovery unit and an economiser respectively reduces the energy used for heating by $12-28 \%$ and the energy used for the required cooling by $33-65 \%$.

In the primary part of HVAC\&R systems, the reciprocating air cooled chiller with a gas boiler provides the lowest total energy consumption and the CCHP system has the highest energy demand. Despite the highest energy demand of the CCHP system, the total $\mathrm{CO}_{2}$ emissions of the system is significantly lower than the other two primary systems.

Finally, the results of this study on the performance evaluation of 36 HVAC\&R systems can be used as a complementary part of the existing building energy benchmarks in order to enhance the performance characterisation assessment of a variety of HVAC\&R 
systems. This is especially applicable to the decision making involved in HVAC\&R system selection carried out in the early stages of a project design process.

\section{Nomenclature}

$C:$ Space capacitance $(k J / K)$

$C_{p}:$ Specific heat capacity $(\mathrm{kJ} / \mathrm{kg} . \mathrm{K})$

$I R G:$ Indoor air quality rating grade (-)

$M:$ Moisture capacitance $(\mathrm{kg})$

$\dot{m}$ : Mass flow rate $(\mathrm{kg} / \mathrm{hr})$

$P$ : Pressure (pa)

$\dot{Q}:$ Net heat gain $(\mathrm{kJ} / \mathrm{hr})$

$\dot{q}:$ Heat transfer $(k J / h r)$

$R:$ Thermal resistance $(K . h r / k J)$

Ratio: Moisture of air to total moisture of space $1-10(\mathrm{~kg} / \mathrm{kg})$

RH : Relative humidity (Percent)

$T:$ Temperature $\left({ }^{\circ} \mathrm{C}\right)$

$t:$ Time $(s)$

TEC : Total energy consumption $(\mathrm{kJ} / \mathrm{hr})$

TGIAQ : Total rating grade for indoor air quality (-)

TGTC : Total rating grade for thermal comfort (-)

TRG: Thermal comfort rating grade (-)

$\dot{W}:$ Moisture flow $(\mathrm{kg} / \mathrm{hr})$

$X:$ Number of occupants (No.) 


\section{Greek style}

$\omega$ : Humidity ratio $(\mathrm{kg} / \mathrm{kg})$

\section{Subscripts}

a: Ambient

b: Boundary surface

c: Convection

cr: Convection and radiation

cplg: Internal zonelair node coupling

e: Number of adjacent boundary surfaces

eff: Effective

fa: Fresh air

gr: Internal gain

h: Hour ' $h$ '

$i$ : Space ' $i$ '

ig: Internal gain

inf: Infiltration

$j:$ the jth energy consuming process within HVAC\&R system

long: Long-wave radiation

ma: Mixed air

n: Number of adjacent spacelair node

$r$ : Radiation heat transfer

re: Return air

sa: Supply air 
schw: Supply chilled water

set: Set-point

shw: Supply hot water

sol: Solar radiation gain through zone windows

star: An artificial node to calculate parallel energy flow

surf: Surface

vent: Ventilation

w: Wall

wall-gain: Predefined wall/win gain 


\section{References}

1. DECC, Climate change act 2008. 2008, London: Department of Energy and Climate Change.

2. DECC, Digest of UK energy statistic. 2010, London: Department of Energy and Climate Change.

3. CT, Building the future, today. 2009, Carbon Trust: London.

4. HC, Programmes to reduce household energy consumption. 2009, House of Commons: London.

5. DCLG, Definition of zero caron home and non-domestic buildings. 2008, Department of Communities and Local Government: London.

6. DTI, Energy consumption in the UK. 2010, Department of trade and industry: London.

7. Parsloe, C. and L.J. Wild, Project management handbook for building services. 1998, Bracknell: Building Services Research and Information Association.

8. Phillips, R., Plan of work: Multi-disciplinary services. RIBA. 2008, London: Royal Institute of British Architects.

9. Potter, M., Planning to build? 1995, London: Construction Industry Research and Information Association.

10. Elovitz, D.M., Selecting the right HVAC system. ASHARE Journal, 2002. 44(1): p. 24-30.

11. Bichiou, Y. and M. Krarti, Optimization of envelope and HVAC systems selection for residential buildings. Energy and Buildings, 2011. 43(12): p. 3373-3382.

12. Lombard, L.P., J. Ortiz, and I.R. Maestro, The map of energy flow in HVAC systems. Applied energy, 2011. 88(12): p. 5020-5031. 
13. Fong, K., V. Hanby, and T. Chowa, HVAC system optimization for energy management by evolutionary programming. Energy and Buildings, 2006. 38(3): p. 220-231.

14. Mossolly, M., K. Ghali, and N. Ghaddar, Optimal control strategy for a multizone air conditioning system using a genetic algorithm. Energy 2009. 34(1): p. 58-66.

15. Shahrestani, M. and R. Yao. An integrated dynamic whole life costing analysis for air distribution systems. in ICAE 2011. 2011. Perugia, Itally: Third International Conference on Applied Energy.

16. CIBSE, Energy efficiency in buildings-Guide F. 2004, Chartered Institution of Building Services Engineers: London.

17. CIBSE-TM46, Energy benchmarks. 2008, London: Chartered Institution of Building Services Engineers.

18. ECG-19, Energy consumption guide 19: Energy use in offices. 2000, London: The Government's Energy Efficiency Best Practice programme.

19. Bruhuns, H., et al., CIBSE review of energy benchmarks for display energy certificates. 2011, Chartered Institution of Building Services Engineers: London.

20. Brigges, R.S., D.B. Crawley, and J.S. Schliesing, Energy requirements of office buildings, vol-1. 1992, Battelle: Pacific Northwest Laboratory for Gas Research Institute.

21. Torcellini, P., et al., DOE Commercial building benchmark models. 2008, California: National Renewable Energy Laboratory.

22. Huang, J., et al., 481 prototypical commercial buildings for 20 urban market areas. 1991, Berkeley, California: Lawrence Berkeley National Laboratory. 
23. Crawley, D.B., et al., Contrasting the capabilities of building energy performance simulation programs. Building and Environment, 2008. 43: p. 661-673.

24. Crawley, D., et al., Contrasting the capabilities of building energy performance simulation programs. 2005: US Department of Energy,University of Strathclyde Energy Systems Research Unit, University of Wisconsin Solar Energy Laboratory, National Renewable Energy Laboratory.

25. Neymark, J. and R. Judkoff, Building Energy Simulation Test and Diagnostic Method for Heating, Ventilation, Air Conditioning Equipment Models-HVAC BESTEST. 2004, International Energy Agency SHC Task22: Building Energy Analysis Tools, NREL Report TP-550-36754.

26. Cuadros, F., et al., A simple procedure to size active solar heating schemes for lowenergy building design. Energy and Buildings, 2007. 39(1): p. 96-104.

27. Macias, M., et al., Application of night cooling concept to social housing design in dry hot climate. Energy and Buildings, 2006. 38(9): p. 1104-1110.

28. Pakanen, J. and S. Karjalainen, Estimating static heat flows in buildings for energy allocation systems. Energy and Buildings, 2006. 38(9): p. 1044-1052.

29. Martínez, P.J., A. García, and J.M. Pinazo, Performance analysis of an air conditioning system driven by natural gas. Energy and Buildings, 2003. 35(7): p. 669-674.

30. Hasan, A. and K. Sirén, Theoretical and computational analysis of closed wet cooling towers and its applications in cooling of buildings. Energy and Buildings, 2002. 34(5): p. 477-486. 
31. Steadman, P., The non-domestic building stock of England and Wales: type, numbers, sizes and ages, in Structure and style conserving 20th century buildings, M. Stratton, Editor. 1997, E \& FN Spon: York. p. 49-72.

32. Steadman, P., et al., A classification of built forms. Environmental and Planning B: Planning and Design, 2000. 27(1): p. 73-91.

33. Klein, S., et al., TRNSYS 17: A Transient System Simulation Program. 2009, Solar Energy Laboratory, University of Wisconsin: Wisconsin.

34. DCLG, Building regulations-conservation of fuel and power: Part L. 1995, London: Department for Communities and Local Government.

35. CIBSE, Environment design-CIBSE guide A. 2006, Chartered Institution of Building Services Engineers: London.

36. HMGovernment, Building regulations-ventilation: Part F. 2010, Her Majesty's Stationery Office: London.

37. SLL, Code for lighting CD-ROM. Vol. CIBSE. 2009, London: Society of Light and Lighting.

38. ASHRAE, ASHRAE handbook-HVAC systems and equipment. 2008, Atlanta: American Society of Heating, Refrigeration and Air-conditioning Engineers.

39. Greeno, R., Building services, technology and design. 1997, London: Longman \& CIOB.

40. GPG-71, Selecting air conditioning systems: A guide for building clients and their advisers. 1993, London: Building Research Energy Conservation Support Unit.

41. Jones, W.P., Air conditioning applications and design. Second ed. 1998, Oxford: Butterworth Heinemann. 
42. BS/EN:15316-4-4, Heating systems in buildings-Method for calculation of system energy requirements and system efficiencies-Part 4-4: Heat generation systems,building-integrated cogeneration systems BS EN 15316-4-4. 2007, British/European Standard.

43. ASHRAE, ANSI/ASHRAE/IESNA Standard-90.1, Energy standard for buildings except low-rise residential buildings. ANSI/ASHRAE/IESNA 2010, Atlanta: American Society of Heating Refrigerating and Air-conditioning Engineers.

44. BS/EN:15251, Indoor environmental input parameters for design and assessment of energy performance of buildings addressing indoor air quality, thermal environment, lighting and acoustics. 2007, London: British/European Standard.

45. Korolija, I., et al., Influence of building parameters and HVAC systems coupling on building energy performance. Energy and Buildings, 2011. 43(6): p. 1247-1253.

46. DETR, Introduction of energy efficiency in offices. 1998, Department of the Environment, Transport and the Regions, Best Practice Programme: London.

47. CIBSE-TM41, Degree-days theory and application. 2006, London: Chartered Institution of Building Services Engineers. 